\title{
RISK FACTORS AND CLINICAL PROFILE OF SEIZURE IN CHILDHOOD
}

\author{
CHOWDHURY RM ${ }^{1}$, ALAM B $^{2}$, SHARMA ZD ${ }^{3}$, DAS KP ${ }^{4}$, HOSSAIN MZ $^{5}$, DEB SR ${ }^{6}$
}

\begin{abstract}
Background: Seizures are a common neurological disorder in the paediatric age group and occur with a frequency of approximately $10 \%$ of children. About $5 \%$ of all children suffer from seizures during first five years of life. Patient with seizure disorders have various underlying causes, so careful analysis of seizure type, accurate diagnosis of underlying cause, indentifying the risk factors are helpful for appropriate management.
\end{abstract}

Objectives: To find out the risk factors, clinical presentation of seizures in children and evaluate the outcome of seizure.

Methods: This prospective study was conducted with 50 patients in the Department of paediatrics of Chittagong Medical College Hospital from July 2007 to June 2008. The child 2 months to 2 years having history of seizure with or without fever was enrolled in this study. Detailed history, thorough clinical examination and relevant investigation was done and compiled in a questionnaire. Data were compiled and analyzed by SPSS software.

Results: Most(48\%) of the study patient was 6 months to 2 years age group and male was predominant(1.9:1). Maximum patient come from urban area with normal developmental milestone(88\%). Meningitis was found as the commonest cause(32\%) followed by febrile seizure(30\%).48(96\%) cases of seizure were generalized and lasted for less than 15 minutes in most cases(76\%). Only 20\% patient had previous history of seizure. Family history was found in $40 \%$ cases of febrile seizure ( $p$ value <.05) and history of perinatal asphyxia were significantly associated with epilepsy. Most (82\%) of the patient were discharged with advice from the hospital.

Conclusion: Children presented with seizure need proper evaluation to identify the causes. Management varies according to clinical presentation. Identify the risk factors, early diagnosis and proper treatment can prevent many dreadful complication as well as death.

Keyword: Seizure, Risk factors.

J Dhaka Med Coll. 2012; 21(2) : 211-217.

\section{Introduction}

Seizures are a common neurological disorder in paediatric age group. It may be defined as a paroxysmal involuntary disturbance of brain function that may manifest as an impairment or loss of consciousness, abnormal motor activity, behavioral abnormalities, sensory disturbances or autonomic dysfunction. Seizures are common in the paediatric age group and occur in approximately $10 \%$ of children and about $5 \%$ of all children suffer from seizure during the first five years of life $^{1}$.
Seizures may be classified as provoked and unprovoked. Some common provogating factors of seizure are fever, CNS infection, acute metabolic disturbance etc. Febrile seizures are an important cause of provoked seizure and affects $3-5 \%$ of all children ${ }^{2}$. The most common cause of unprovoked seizure is epilepsy. Two or more unprovoked seizures occurring in 24 hours apart are called epilepsy ${ }^{3}$. Worldwide 3.5 millions people developed epilepsy annually; about $40 \%$ of these are under 15 years. More

1. Dr. Rumpa Mani Chowdhury, Resident, Phase-B, Department of Neonatology, BSMMU, Shahbagh, Dhaka. Mobile-01816356806, E-mail: kdas33@yahoo.com.

2. Prof. Badrul Alam, Professor \& Head of the Department of Paediatrics, USTC, Chittagong.

3. Prof. Zhulan Das Sharma, Professor \& Head of the Department of Paediatrics, North East Medical College, Chittagong.

4. Dr. Krishna Priya Das, Assistant Professor, Department of Orthopaedic Surgery, Bangabandhu Sheikh Mujib Medical University, Shahbagh, Dhaka, Bangladesh.

5. Dr. Mohammad Zaid Hossain, Assistant Professor, Department of Medicine, DMCH, Dhaka

6. Dr. Sudip Ranjan Deb, Resident Physician, Dhaka Medical College Hospital, Dhaka

Correspondence: Dr. Rumpa Mani Chowdhury, Resident, Phase-B, Department of Neonatology, BSMMU, Shahbagh, Dhaka. E-mail: kdas33@yahoo.com. 
than $80 \%$ of them live in less developed countries $^{4}$. Incidence of epilepsy is $50 / 100,000$ per year in developed countries and 100-190/ 100,000 per year in developing. Generalized seizures are more common than partial seizure in less than five children ${ }^{5}$. Epilepsy is more common in developing countries than developed countries because of increased perinatal problems like birth asphyxia, sepsis, bilirubin encephalopathy, CNS infections, consanguinity related metabolic diseases and head trauma ${ }^{2}$. Seizures may signal potentially serious underlying systemic or Central Nervous System (CNS) disorder that requires thorough investigation and management. In addition to risk of death, Pneumococcal meningitis in children causes severe disabilities among survivor. In Bangladesh epidemiological surveys confirm that seizure disorders are common. One study showing prevalence rate of epilepsy is 68 / 1000 for 'any seizure history' and 9/1000 for 'any unprovoked seizure' in children aged 2 to 9 year ${ }^{6}$. A large number of patients admitted in paediatric inpatients department are with the diagnosis of seizure disorders of various underlying causes. So, careful analysis of seizure types, accurate diagnosis of underlying causes, appropriate management and monitoring is essential. Extensive research has been done in this field in the developed world. Some studies also enrolled in Bangladesh but in Chittagong there is no such type of study had been conducted yet. So, the aim of this study is to identify the risk factors, observe the clinical profile and also evaluate the outcome of seizures in children.

\section{Patients and methods}

This prospective study was done in the Department of Paediatrics, Chittagong Medical College Hospital from July 2007 to June 2008. All children admitted having history of seizure with or without fever in between two months to twelve years of age were included in the study. Children having congenital malformation, cerebral palsy, hepatic and renal failures were excluded from the study. Total numbers of patients were 50.The dependent variable was seizure and independable variable were perinatal asphyxia, neonatal seizure, family history of febrile seizure, family history of epilepsy, previous neurological disabilities, mental retardation, anaemia, malnutrition.

\section{Study Procedure:}

A detailed history including: nature, duration, precipitating factors, number of attacks, association with fever, family history of seizure etc, elaborate birth history and developmental milestones will be noted. Careful physical examination will be done for every patient. The investigations will be done according to the clinical suspicion and within the limitation of hospital facilities and affordability of the patients' party. Neuroimaging procedures like USG of brain, CT scan, MRI and EEG will be done whenever indicated and if possible. All findings will be recorded in a predesigned questionnaire. The treatment of specific causes will be done. Patients will be followed up regularly, weekly for four weeks then monthly for six months. Outcome will be evaluated as duration of illness, development of complications and death. Data will be compiled and analyzed by SPSS software.

\section{Results}

A total of 50 cases of both sexes and age group of 2 months to 12 years were studied. Most (48.0\%) of the study patients was $6 \mathrm{~m}-2$ years age group. $33(66.0 \%)$ were male and rest $17(34.0 \%)$ were female patients. Maximum 31(62.0\%) number of patients lived in urban area. Middle income family was predominant in the study patients. Normal development mile stone was in $44(88.0 \%)$ and delayed was in $6(12.0 \%$ of the patients (Table-I). Table (II) shows meningitis was the commonest cause which included 16 (32\%) patient among all, followed by febrile seizure 15 (30\%), epilepsy $8(16 \%)$, cerebral malaria $7(14 \%)$, encephalitis $3(6 \%)$ and subaute, sclerosing panencephalitis $1(2 \%)$ patient. Seizures lasted for less than 15 minutes in 38 (76\%) cases and in $12(24 \%)$ cases it lasted for more than 15 minutes. In 48 (96\%) cases seizures were generalized in nature; remaining $2(4 \%)$ cases had focal seizures. 1 patient from epilepsy and 1 patient from febrile seizure had focal seizure (table III).Most of the causes were found among who had no previous history of seizure, febrile seizure $5(33.3 \%)$, epilepsy $4(50.0 \%)$ and subacute sclerosing panencephalitis $1(100.0 \%)$ were found among who had history of seizure (Table IV). Table (V) shows family history of febrile seizure was significantly $(p<0.05)$ associated with febrile seizure where OR $0.09(0.01<\mathrm{CI}<0.64)$ and the others risk factors are not statistically significant $(p>0.05)$. There were no risk factors significantly associated 
with CNS infection ( $p>0.05)$. History of perinatal asphyxia was significantly $(\mathrm{p}<0.05)$ associated with epilepsy where OR $0.11(0.01<\mathrm{CI}<0.77)$ and the others risk factors are not statistically significant ( $p>0.05)$. Table (VI) shows all cases of febrile seizure, aseptic meningitis and epilepsy (100.0\%)were recovered completely. $7(70 \%)$ cases of acute pyogenic meningitis,
$1(50 \%)$ case of tubercular meningitis and $6(85.7 \%)$ cases of cerebral malaria were fully recovered but rest of the cases had sequlae during discharge. Death occur $1(10.0 \%)$ case of acute pyogenic meningitis, $2(66.7 \%)$ cases of tubercular meningitis, $1(14.3 \%)$ case of cerebral malaria and $1(100 \%)$ case of subacute sclerosing panencephalitis.

\section{Table-I}

Socio demographic profile and developmental milestone $(n=50)$.

\begin{tabular}{llcc}
\hline Parameter & Value & $\mathrm{n}$ & $\%$ \\
\hline Age & $2-6$ month & 4 & 8.0 \\
& $>6$ m-2 years & 24 & 48.0 \\
& $>2-5$ years & 12 & 24.0 \\
Sex & 5-12 years & 10 & 10.0 \\
\multirow{2}{*}{ Residence } & Male & 33 & 66.0 \\
\multirow{2}{*}{ Socioeconomic status } & Female & 17 & 34.0 \\
& Urban & 31 & 62.0 \\
\multirow{2}{*}{ Developmental milestone } & Rural & 19 & 38.0 \\
& Lower income (<5000 taka/month) & 16 & 32.0 \\
& Middle income (5000-10,000 taka/ month) & 19 & 38.0 \\
& Higher income (>10,000 taka month) & 15 & 30.0 \\
& Normal & 44 & 88.0 \\
& Delayed & 6 & 12.0 \\
\hline
\end{tabular}

Table-II

Etiology of seizure in children $(N=50)$

\begin{tabular}{lcc}
\hline Causes & Number $(\mathrm{N}=50)$ & Percentage $(100 \%)$ \\
\hline Febrile seizure & 15 & 30.0 \\
Acute pyogenic meningitis & 10 & 20.0 \\
Aseptic meningitis & 4 & 8.0 \\
Tubercular meningitis & 2 & 4.0 \\
Encephalitis & 3 & 6.0 \\
Cerebral malaria & 7 & 14.0 \\
Epilepsy & 8 & 16.0 \\
Subacute, sclerosing panencephalitis & 1 & 2.0 \\
\hline
\end{tabular}

Table-III

Duration and nature of seizure $(n=50)$

\begin{tabular}{lcccc}
\hline Causes & \multicolumn{2}{c}{ Duration } & \multicolumn{2}{c}{ +Nature } \\
& $<15$ minutes & $>15$ minutes & Generalized & Focal \\
& $\mathrm{n}(\%)$ & $\mathrm{n}(\%)$ & $\mathrm{n}(\%)$ & $\mathrm{n}(\%)$ \\
\hline Febrile seizure & $14(28.0)$ & $1(2.0)$ & $14(28)$ & $1(2)$ \\
Acute pyogenic meningitis & $8(16.0)$ & $2(4.0)$ & $10(20)$ & $0(0)$ \\
Aseptic meningitis & $3(6.0)$ & $1(2.0)$ & $4(8)$ & $0(0)$ \\
Tubercular meningitis & $0(0.0)$ & $2(4.0)$ & $2(4)$ & $0(0)$ \\
Encephalitis & $1(2.0)$ & $2(4.0)$ & $3(6)$ & $0(0)$ \\
Cerebral malaria & $5(10.0)$ & $2(4.0)$ & $7(14)$ & $0(0)$ \\
Epilepsy & $7(14.0)$ & $1(2.0)$ & $7(14)$ & $1(2)$ \\
Subacute sclerosing panencephalitis & $0(0.0)$ & $1(2.0)$ & $1(2)$ & $0(0)$ \\
\hline Total & $38(76)$ & $12(24)$ & $48(96)$ & $2(4)$ \\
\hline
\end{tabular}


Table-IV

Previous history of seizure $(n=50)$

\begin{tabular}{lccc}
\hline Causes & \multicolumn{3}{c}{ Previous history } \\
\cline { 2 - 4 } & Total & $\begin{array}{c}\text { Absent } \\
\mathrm{n}(\%)\end{array}$ & $\begin{array}{c}\text { Present } \\
\mathrm{n}(\%)\end{array}$ \\
\hline Febrile seizure & & $10(66.7)$ & $5(33.3)$ \\
Acute pyogenic meningitis & 15 & $10(100.0)$ & $0(0.0)$ \\
Aseptic meningitis & 10 & $4(100.0)$ & $0(0.0)$ \\
Tubercular meningitis & 4 & $2(100.0)$ & $0(0.0)$ \\
Encephalitis & 2 & $3(100.0)$ & $0(0.0)$ \\
Cerebral malaria & 3 & $7(100.0)$ & $0(0.0)$ \\
Epilepsy & 7 & $4(50.0)$ & $4(50.0)$ \\
Subacute sclerosing panencephalitis & 8 & $0(0.0)$ & $1(100.0)$ \\
\hline
\end{tabular}

Table-V

Association of risk factors $(n=50)$

\begin{tabular}{|c|c|c|c|c|c|c|}
\hline \multirow[t]{2}{*}{ Variable } & \multicolumn{3}{|c|}{ Febrile seizure $(n=15)$} & \multirow{2}{*}{ Epilepsy $(\mathrm{n}=8)$} & \multicolumn{2}{|c|}{ CNS infection $(\mathrm{n}=27)$} \\
\hline & $\mathrm{n}(\%)$ & odds ratio $(95 \% \mathrm{CI})$ & $\mathrm{n}(\%)$ & & $\mathrm{n}(\%)$ & Odds ratio $(95 \% \mathrm{CI})$ \\
\hline History of & $2(13.3)$ & $\mathrm{p}=0.549^{\mathrm{NS}}$ & $4(50)$ & $\mathrm{p}=0.015^{\mathrm{s}}$ & $2(7.4)$ & $\mathrm{p}=0.079^{\mathrm{NS}}$ \\
\hline perinatal asphyxia & & $\begin{array}{l}\text { OR1.34 } \\
0.01 \text { to0.77) }\end{array}$ & & $\begin{array}{l}\text { OR0.11 } \\
\text { (0.20to11.2) }\end{array}$ & & $\begin{array}{l}\text { OR4.41 } \\
\quad(0.67 \text { to } 36.3)\end{array}$ \\
\hline $\begin{array}{l}\text { History of } \\
\text { neonatal seizure }\end{array}$ & $1(6.7)$ & $\begin{array}{l}p=0.654^{N S} \\
\text { OR } 1.31 \\
(0.10 \text { to } 35.84)\end{array}$ & $2(25)$ & $\begin{array}{l}\mathrm{p}=0.115^{\mathrm{NS}} \\
\text { OR } 0.15 \\
\text { (0.01to } 1.89 \text { ) }\end{array}$ & $1(3.7)$ & $\begin{array}{l}p=0.246^{\mathrm{NS}} \\
\text { OR0.26 } \\
(0.1 \text { to } 3.15)\end{array}$ \\
\hline $\begin{array}{l}\text { Family history of } \\
\text { febrile seizure }\end{array}$ & $6(40)$ & $\begin{array}{l}p=0.005^{\mathrm{S}} \\
\text { OR0.09 } \\
\text { (0.01 to0.6) }\end{array}$ & $1(12.5)$ & $\begin{array}{l}\mathrm{p}=0.621^{\mathrm{NS}} \\
\text { OR0.71 } \\
\text { (0.03to7.79) }\end{array}$ & $1(3.7)$ & $\begin{array}{l}p=0.521^{\mathrm{NS}} \\
\text { OR0.61 } \\
(0.03 \text { to } 7.79)\end{array}$ \\
\hline $\begin{array}{l}\text { Family historyof } \\
\text { epilepsy }\end{array}$ & $2(13.3)$ & $\begin{array}{l}\mathrm{p}=0.591^{\mathrm{NS}} \\
\text { ORO.O9 } \\
(0.01 \text { to0.64) }\end{array}$ & $1(12.5)$ & $\begin{array}{l}p=0.514^{\mathrm{NS}} \\
\text { OR } 1.86 \\
(0.00 \text { to } 26.51)\end{array}$ & $1(3.7)$ & $\begin{array}{l}\mathrm{p}=0.063^{\mathrm{NS}} \\
\text { OR0.14 } \\
(0.01 \text { to } 1.43)\end{array}$ \\
\hline $\begin{array}{l}\text { Pre-existing } \\
\text { neurological } \\
\text { disorder }\end{array}$ & $0(0)$ & $\begin{array}{l}\mathrm{p}=0.333^{\mathrm{NS}} \\
\text { ORO.O } \\
\text { (O.Oto5.52) }\end{array}$ & $1(12.5)$ & $\begin{array}{l}\mathrm{p}=0.297^{\mathrm{NS}} \\
\text { OR0.17 } \\
(0.00 \text { to } 7.19)\end{array}$ & $1(3.7)$ & $\begin{array}{l}\mathrm{p}=0.713^{\mathrm{NS}} \\
\text { OR0.85 } \\
(0.02 \text { to33.3) }\end{array}$ \\
\hline $\begin{array}{l}\text { Mental } \\
\text { retardation } 1\end{array}$ & $0(0)$ & $\begin{array}{l}\mathrm{p}=0.486^{\mathrm{NS}} \\
\text { OR } 0.0 \\
(0.0 \text { to } 10.17)\end{array}$ & $1(12.5)$ & $\begin{array}{l}\mathrm{p}=0.297^{\mathrm{NS}} \\
\text { OR0.17 } \\
\text { (0.00to } 7.19)\end{array}$ & $1(3.7)$ & $\begin{array}{l}\mathrm{p}=0.713^{\mathrm{NS}} \\
\text { OR0.85 } \\
(0.02 \text { to33.3) }\end{array}$ \\
\hline Anaemia & $5(33.3)$ & $\begin{array}{l}\mathrm{P}=0.253^{\mathrm{NS}} \\
\text { OR0.84 } \\
(0.11 \text { to } 7.62)\end{array}$ & $2(25)$ & $\begin{array}{l}p=0.626^{\mathrm{NS}} \\
\text { OR0.39 } \\
(0.13 \text { to8.00) }\end{array}$ & $5(18.5)$ & $\begin{array}{l}\mathrm{p}=0.325^{\mathrm{NS}} \\
\text { OR0.52 } \\
(0.11 \text { to } 2.30)\end{array}$ \\
\hline Malnutrition & $3(20.0)$ & $\begin{array}{l}\mathrm{p}=0.989^{\mathrm{NS}} \\
\text { OR0.63 } \\
\text { (0.11to3.19) }\end{array}$ & $3(37.5)$ & $\begin{array}{l}\mathrm{p}=0.341^{\mathrm{NS}} \\
\text { OR0.52 } \\
(0.08 \text { to3.39) }\end{array}$ & $7(25.9)$ & $\begin{array}{l}\quad \mathrm{p}=0.398^{\mathrm{ns}} \\
\text { OR0.99 } \\
(0.24 \text { to } 4.21)\end{array}$ \\
\hline
\end{tabular}

Association of risk factors $(\mathrm{n}=50)$

$\mathrm{p}$ value reached from chi square test, $\mathrm{S}=$ Significant $(<0.05), \mathrm{NS}=$ not significant $(>0.05), \mathrm{OR}=$ Odd ratio, $\mathrm{CI}=$ confidence interval. 
Table-VI

Outcome $(n=50)$

\begin{tabular}{lccc}
\hline Causes & \multicolumn{2}{c}{ Discharge } & Death \\
& $\begin{array}{c}\text { Full Recovery } \\
\mathrm{n}(\%)\end{array}$ & $\begin{array}{c}\text { Sequelae } \\
\mathrm{n}(\%)\end{array}$ & $\mathrm{n}(\%)$ \\
\hline Febrile seizure & $15(100.0)$ & $0(0.0)$ & $0(0.0)$ \\
Acute pyogenic meningitis & $7(70.0)$ & $2(20.0)$ & $1(10.0)$ \\
Aseptic meningitis & $4(100.0)$ & $0(0.0)$ & $0(0.0)$ \\
Tubercular meningitis & $1(50.0)$ & $1(50.0)$ & $0(0.0)$ \\
Encephalitis & $0(0.0)$ & $1(33.3)$ & $2(66.7)$ \\
Cerebral malaria & $6(85.7)$ & $0(0.0)$ & $1(14.3)$ \\
Epilepsy & $8(100.0)$ & $0(0.0)$ & $0(0.0)$ \\
Subacute sclerosing panencephalitis & $0(0.0)$ & $0(0.0)$ & $1(100.0)$ \\
\hline
\end{tabular}

\section{Discussion}

Seizures are common neurological disorder in children. About 5\% of allchildren suffer from seizures during first five years of life ${ }^{7}$. Illingworth reported that convulsions occur in $7 \%$ of all children in the first five years of life and in about $1 \%$ of all newborn babies ${ }^{8}$. The age of the patient ranged from 2 months to 12 years. The majority of patients were under 2 years of age $(56 \%)$ i.e. frequency of convulsion was found higher in children under 2 years of age .A similar frequency was shown by Nazrul $(67 \%)^{9}$ and Begum $(65.44 \%)^{10}$ but there was a difference with the study at $\operatorname{Islam}(47.33 \%)^{11}$. This may be due to the fact that the sample sizes in that study was large in comparison to present study. In febrile seizure 13 cases were found between 6 months to 2 years which was about $86.66 \%$ of the total. Farewell et. al showed about $64 \%$ between 12 to 23 months of age ${ }^{12}$. In pyogenic meningitis $90 \%$ of patients were under 5 years of age which was consistent with the study of Antilla (87\%) ${ }^{13}$. Male, female ratio of seizures in this study was $1: 94: 1$. The fact was well documented by Rutter N.et.al $(1: 7: 1)^{14}$ and by Islam $(2: 48: 1)^{11}$.Male preponderance of the present study in our country may be due to that in our society boys are treated preferentially in poor socio-economic groups. The incidence of epilepsy was slightly higher in males than females in the study done by Golden et. $\mathrm{Al}^{15}$. But in the present series males $(75 \%)$ were more affected than females. This finding can be explained by the fact that female child are more likely to have social problems if they are diagnosed as epileptics. In this present study, it was found that the rural patients $(62.0 \%)$ and the middle class family income $(38.0 \%)$ group were predominant and development milestone status of the children was $88.0 \%$ normal. The finding of the present study is closely resemble with Banu et al $(2003)^{5}$. Febrile seizure accounted for $30 \%$ of cases in the present series which was consistent with the study of Islam $(24.37 \%)^{11}$, Begum (25.45\%) ${ }^{10}$ and Absar (25\%) ${ }^{16}$. Other causes of seizures were pyogenic meningitis, aseptic meningitis, tubercular meningitis, encephalitis, cerebral malaria, epilepsy, and sub acute sclerosing panencephalitis. Intracranial infection from the major component of seizures in the present series $54 \%$. This is not consistent with the study of Islam $(36 \%)^{11}$. This may be due to higher incidence of cerebral malaria in this region. In the present series in $76 \%$ cases the seizure lasted for less than 15 minutes which was comparable with the study of Nazrul $(77 \%){ }^{9}$. Christopher studied on the extent of brain damage by prolonged seizure ${ }^{17}$. He concluded that if seizures cause brain damages it happens very rarely. But the aim of treatment should be to terminate such seizures as quickly as possible and the management of status epilepticus should still be regarded as a medical emergency. Seizures were generalized 
in most of the patients (96\%) in the present study which was slightly higher than study done by Islam $(85.33 \%)^{11}$. Focal seizures were found in 2 patients; 1 from epilepsy and 1 form pyogenic meningitis.

In this study $80 \%$ patient had previous history of seizures and $20 \%$ presented as a new case. CSF study was done in 29 patients. In showed normal finding in $16(55.17 \%)$ cases and abnormal findings in $13(44.42 \%)$ cases. In this current series it was observed that family history of febrile seizure were significantly $(p<0.05)$ associated with febrile seizure where $0.09(0.01<\mathrm{CI}<0.64)$. On the other hand history of perinatal asphyxia were also significantly $(\mathrm{p}<0.05)$ associated with epilepsy where $0.11(0.01<\mathrm{CI}<0.77)$. There was no significant risk factor was found for CNS infection family history was found in $6(40 \%)$ cases of febrile seizure, which is comparable with the study of Islam $(40 \%)^{11}$ and Lewis et al $(40 \%)^{18}$. History of perinatal asphyxia was found in 4 (50\%) cases of epilepsy, which is comparable with the study of Banu et al (46.4\%). ${ }^{5}$ Febrile seizure is a benign condition, so all paitent $(100 \%)$ recovered fully without sequelae. If acute pyogenic meningitis is early diagnosed and properly managed most of the patient recover fully7 $(70.0 \%)$, but some unavoidable sequelae $2(20 \%)$ and death $1(10 \%)$ can also occur. Tubercular meningitis is a dreadful disease; early treatment can prevent sequelae $1(50.0 \%)$. Early referral and treatment can save the life of most of cerebral malaria patient $6(85.7 \%)$. SSPE is a grave disease, all patient die regardless of treatment. Only prevention of measles can prevent this situation. Vaccinated against susceptible organism can prevent meningitis and identification of organism, proper treatment with appropriate antibiotics and duration can prevent further complication. Both the patients of tubercular meningitis were not immunized with BCG vaccine. Early diagnosis and treatment can prevent dreadful complication and the patient was fully recovered after anti TB treatment. As the study was done with small sample size (50), overall picture of the population could not be seen. To get a correct idea about the management and outcome of seizure in children, further large study will be required.

\section{Conclusion}

The study indicates that seizure disorders are a common cause of hospital admission in our children population. It is alarming for both parents and the children affected. Family history of febrile seizure was found significant risk factor for febrile seizure. History of perinatal asphyxia was significantly associated with epilepsy. It gives the clue that there are many preventable risk factors of seizure which can be prevented by different measures like proper counseling of parents, vaccination and public health measure. As the sample size was small only 50 , to evaluate all these situations in a more elaborate way this subject is open for further study.

\section{References}

1. Johnston MV. Seizure in childhood. In: Kliegman RM, Behrman RE, Jenson HB, Stanton BF, editors. Nelson Textbook of Pediatrics. $18^{\text {th }}$ ed. Philadelphia: Saunders; 2007.2457-75.

2. Kalra v. Seizure Disorders and Epilepsy. 1st edn. New Delhi: Avichal Publishing company; 2002. 49-77.

3. ILAE. Commission on classification and Terminology of International League Against Epilepsy: Proposal for revised classification of epilepsies and epileptic syndrome. Epilepsia 1989; 30: 1389-99.

4. Pellock JM, Dodson WE, Blaise FD. Epidemiology of epilepsy in children. Seizure 1998; 7 : 281-8. 10 Treggiari MM, Walder B, Suter PM, et al. Current Opinion Neurol 2003; 16:166-70.

5. Sander JW. The use of Antiepileptic drugsPrinciple and practice. Epilepsia 2004; 45 (56): 28-34.

6. Durkin MS, Davidson LL, Hasan MZ, Khan N et al. Estimate of the prevalence of childhood seizure disorders in communities where professional resources are scarce: results from Bangladesh, Jamica and Pakistan. Paediar Perinatal Epidemiol 1992; $6: 166-80$.

7. Ghai OP. Convulsions, Essential Paediatrics. $3^{\text {rd }}$ edn. Bombay: Japee Brothers; 1993. 315.

8. Illingworth RS. Common symptoms of diseases in children. $7^{\text {th }}$ ed. Oxford: Blackwell scientific publication; 1983. 234-50.

9. Islam N. Convulsion in children. FCPS Dissertation: BCPS.1991. 
10. Begum H. Aetiology and hospital outcome of convultion in children. FCPS Dissertation: BCPS. 1996

11. Islam MM, Tabib SB, Islam A, Rehman MM. Convulsion disorder in Children; A study of 150 hospitalized cases. Ban J Med Science 1995; 2: 11-5

12. Farwell RL, Gregary B, Stephen S et al. First febrile seizures, Characteristics of the child and the illness. Clini Paediatr. 1994; 4:263-267.

13. Antilla N, Himberg JJ, Peltola H. Precise quantification of fever in childhood Bacterial Meningitis. Clini Pediatri. 1992; 6: 221-7.
14. Rutter N. Route of routine investigations in children presenting with their first febrile convulsion. Arch Dis child 1977; 52:188-91.

15. Eli S, Goldens S et al. Merritt's textbook of Neurology. 8th ed. Varghese: Lewis P. Rowland lea and Febiger; 1989.185-94.

16. Absar N. Convulsion in Children. FCPS Dissertation: BCPS. 1985.

17. Christopher M. Do seizures damage the brain? Arch Dis child 1998; 78: 78-84.

18. Lewis HM, Perry JV et al. Role of virus in febrile convulsion. Arch Dis child 1979; 54:869-76. 